A. D. Paterson

\title{
To: Biason-Lauber A, Boehm B, Lang-Muritano M et al. (2005) Association of childhood type 1 diabetes mellitus with a variant of PAX4: possible link to beta cell regenerative capacity. Diabetologia 48:900-905
}

Received: 21 April 2005 / Accepted: 18 May 2005 / Published online: 13 August 2005

(C) Springer-Verlag 2005

To the Editor:

In Table 1 of the paper by Biason-Lauber et al. [1], there are a number of errors in the statistical calculations and significant departures from Hardy-Weinberg equilibrium.

First, the $\chi^{2}$ tests provided for association of genotype with type 1 diabetes are incorrect. I have recalculated them based on converting the genotype proportions into counts, and have analysed them using PROC FREQ in SAS, Version 9.1 for Windows (Cary, NC, USA). The correct values and $d f$ are as follows: Swiss sample $\chi^{2}=149,2 d f$, $p<0.0001$; German sample $\chi^{2}=75,2 \mathrm{df}, p<0.0001$.

Further, it is not clear what the comparison group was for the antibody-positive, type 1 diabetes-negative subjects.

Of greatest concern is that the case and control groups for both the Swiss and German study populations deviate significantly from Hardy-Weinberg equilibrium (Swiss cases $p<0.0005$, Swiss control subjects $p<0.0001$, German cases $p<0.05$, German control subjects $p<0.0001)$. No Hardy-Weinberg calculations were presented in the paper. In the Subjects and methods, it is indicated that two different genotyping methods were used to generate the data, but it was not stated which individuals were genotyped by which method(s).

Finally, the relative risk calculation for the $\mathrm{C} / \mathrm{C}$ genotype compared with the other genotypes (footnote a to Table 1) is incorrect if it is calculated for either the combined Swiss and German samples or the individual samples. The correct analysis for the combined Swiss and German samples produces an odds ratio of 6.1 (95\% CI 4.7-7.9).

As with all genetic studies, confirmation of the finding of association in independent populations by independent investigators will be required.

\section{References}

1. Biason-Lauber A, Boehm B, Lang-Muritano M et al (2005) Association of childhood type 1 diabetes mellitus with a variant of PAX4: possible link to beta cell regenerative capacity. Diabetologia 48:900-905

\footnotetext{
A. D. Paterson $(\square)$

Program in Genetics and Genomic Biology,

The Hospital for Sick Children,

555 University Avenue,

Toronto, Ontario, Canada, M5G 1X8

e-mail: andrew.paterson@utoronto.ca

Tel.: +1-416-8136994

Fax: +1-416-8132150
} 